\title{
Role of Academic Advisors in the Success of Engineering Students
}

\author{
Adeel Khali1 ${ }^{*}$, Jessica Williamson \\ Systems and Mechanical Engineering, Southern Polytechnic State University, 1100 South Marietta Parkway, SE, Marietta, GA. 30060 \\ *Corresponding Author:akhalid2@spsu.edu
}

Copyright (C) 2014 Horizon Research Publishing All rights reserved

\begin{abstract}
The role of an academic advisor is emphasized in this study. There is only one academic advisor in the School of Engineering at the Southern Polytechnic State University (SPSU). The academic advisor addresses the advising needs of more than 1,200 engineering students. The importance of professional advising and the need for higher advisor-student ratio is highlighted. Both advisor and student perspectives are addressed in this paper. Student data is collected through a survey to analyze their understanding of the difference between academic and faculty advisors. The survey also reveals the importance of an academic advisor for the retention, progression and graduation success of the engineering students.
\end{abstract}

Keywords Academic Advisor, Faculty Advisor, Career, Curriculum

\section{Introduction}

Many high school students will realize early on that they want to become an engineer of some sort for various reasons. These reasons include but are not limited to; excelling at mathematics, prompting by teachers or parents, expressing a great deal of curiosity, enjoying taking things apart and putting them back together, or a combination of these factors. Even though many students are drawn to the field of engineering, most are not clear when it comes to choosing a specific engineering discipline. Sometimes they may become confused or frustrated with their chosen program of study and end up changing to another discipline. To retain these curious minds, it is important that proper advice is given to them so they not only choose the sub-specialty that is right for them but also stay interested and engaged. After having decided on their major and sub-specialty, students often need further advice on what classes to take within their discipline. Over the years, engineering disciplines have become vast and deep. There are numerous sub-specializations available. It can be expected that these sub-areas of specializations will continue to increase in number, giving students a multitude of choices. The academic advisor's job is crucial in helping students make the important decisions in determining their major. This task is as essential as that of a parent or a professor. Making key decisions such as choosing a major can affect not only the student's future career goals, but also, in some cases, the course of their lives. In this study, we explore some of the common questions that students need help with while seeking academic advisement. We also analyze the central role academic advisors play in helping retain students. Retention is crucial to a University's growth. Academic advisors try to keep students interested and engaged by building a successful rapport with them. This allows students to feel comfortable in an academic setting and they tend to be motivated to follow through and progress to graduation with degrees in engineering. The passion they possess about their field helps to fuel their desire to continue, despite the challenges they face, and these students end up as successful individuals.

\section{Demands and Challenges of Advisement}

Fritz et al. indicate that it is important to effectively advise students (Grupe, 2002) (Grupe, 2002). Well advised students are (a) more likely to enroll, (b) less likely to take classes that do not contribute towards graduation, (c) more likely to enjoy college, (d) more apt to persist to graduation. Advising is labor intensive because it generally requires at least one hour of counseling time per student per session. Several sessions of this length may be required to guide students on the right track and answer all their questions. For most colleges and universities, a large number of students are served by the limited number of available advisors. Lowe and Toney indicate that academic advisement is often considered a minor activity at most colleges and universities (Lowe, 2002). (Lowe, 2002) It is an inconsistently administered process. The needs of many students are not met by the systems in place and failure to provide adequate advisement can lead to more students dropping out early. Lowe and Toney also note that academic advisement should 
begin in the early stages of a student's academic planning in order to be most effective. These challenges apply at both graduate and undergraduate levels (Selke \& Wong, 1993). Frost demonstrates through a survey that students are dissatisfied with advising, which they describe as a low status, prescriptive function addressing their informational needs only (Frost, 1993). Hutchins et al. have demonstrated that group interactions can serve as a vehicle to facilitate faculty-student advisement (E. \& Miller, 1979) (E. \& Miller, 1979). Effective advisement has been called a critical link to student retention (Habley, 2009) .Several other studies have demonstrated the importance of advising in undergraduate education, and have pointed out the demands and challenges (Jenkins, 1992) (William L. Heward, 1990). Efforts have been made to make the advisement an automated process using computer assisted programs.

\section{Computer Assisted Advisement Programs}

Some of the challenges of proper advisement can be addressed by the use of computer assisted advising programs. Rao et al. suggest an automated expert system for student advisement (T. M. Rao, 1987). Lowe et al. developed an expert system based on artificial intelligence to replicate the process actually used by experts in the advisement area (Lowe, 2002). SPSU uses DegreeWorks ${ }^{\circledR}$ software to help chart the students' progress towards graduation (T. M. Rao, 1987) (T. M. Rao, 1987). It is a tool for advising, transfer articulation, and degree audit. It gives the students an opportunity to see their degree program from the perspective of both an advisor and those in the registrar's office. It gives students the ability to find out what courses they need to graduate and where they are in terms of their degrees. Degree requirements are put into the system based on department or major. Students need to develop a graduation plan with their advisor. Once the plan has been developed, DegreeWorks ${ }^{\circledR}$ applies that plan to graduation requirements and shows where each planned course will fit. It shows a progress bar for degree completion. In addition to providing degree requirements, it can also be used as an academic planning tool. Students benefit from the built-in GPA calculators. There are several tools that both students and advisors can utilize. For example, one tool shows students their current classes and allows them to speculate about what grade they might earn. It can project a GPA based on whatever they decide to input. There is also a "what if" tab that allows students to select another major to see how courses already completed would fit into that degree program.

A recently discovered advising tool called Course Shark,

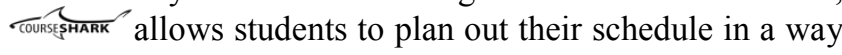
that is both visually appealing and easy to understand (CourseShark, 2013) (CourseShark, 2013). It significantly improves the time it takes to assist students with scheduling classes by day and time. It is very useful during periods of registration when the advisor is inundated with student requests.

Despite all its advantages, the computer assisted advisement programs have their limitations. Degree requirements change in each department from time to time. These requirements will continue to be refined and changed to keep the programs current. These changes pose new challenges that necessitate the need for students to talk to the academic advisor for up-to-date information. Although the computer assisted advisement programs are helpful, they are not a substitute for academic advisement.

\section{Advisor and Student Perspectives}

This study is based on an interview with the academic advisor for the School of Engineering at Southern Polytechnic State University (SPSU). The advisor has a busy schedule with back to back appointments all day long Monday-Friday. The demand is highest during the registration period and the first few weeks of the semester. In the interview, the advisor is asked a set of questions. These questions help the reader understand the general advice given to undergraduate students. It reveals the most common questions that students ask and the biggest complaints they have. Some of the effective advising practices are highlighted. The decisions of what disciplines and career choices to pursue are ultimately that of the students. It is both difficult and ill-advised for an advisor to make a decision for a student. The advisor's primary focus is to make the student aware of the various choices available.

Advisors can also help with guiding students in determining what the best options are for them. Student perspectives are gathered through a student survey. It highlights the most pressing needs that students have. It reveals how frequently students see the advisor. It breaks down those who seek advice by class standing. The survey also reveals how students distinguish between their expectations of the academic advisor from that of a faculty advisor. Finally, the survey shows the number of students utilizing the advising services. The study demonstrates the need for more academic advisors in engineering schools.

\section{Academic Advisor's Perspective}

For the purpose of this study, the academic advisor is referred to as a person who helps students obtain what they are seeking regarding their degree requirements. The academic advisor guides students through their college experience. They are there to help students determine what they want to do and what it will take to get there. More specifically, academic advisors help students identify such things as the correct major, curriculum, minor, certificates, internships, campus resources and much more. While all degree requirements are posted on the registrar's website, students are encouraged to check in with the academic advisor at least once a semester if not more to make sure they 
are staying on track. Students may also learn about other opportunities that can further enhance their ability to reach their future goals. There are many resources available on campus for helping students address the academic difficulties they may be having. One of these resources is on campus tutoring for those struggling in their classes. The academic advisor can help point to the program that can best address the student's situation.

On the other hand, the faculty advisor is an academic professor who is usually the subject matter expert. Each student is assigned a faculty advisor. Students refer to the faculty advisor for specific questions regarding the area of study and career interests in a particular field.

In this study, the need and the importance of the academic advisor is emphasized. The questions for the academic advisor and her respective answers are listed as follows.

\subsection{What are Some of the Questions that Students Ask Most Often}

The most common question deals with what courses students need for the upcoming semester and in what order courses should be taken in future semesters. This is when students seek help with laying out the plan of study. This engineering advisor has been tasked to primarily focus on freshman, sophomore and new transfer students to the university. Because of a heavy load and time constraints, the advisor sometimes refers junior and senior students to the faculty advisors or department chairs. Although, as shown later, it turns out that the junior and senior students tend to seek advice from the academic advisor more frequently than freshman and sophomore students. One proposed reason for this is word of mouth from one student to another. These upperclassmen mainly ask questions about being on track for graduation and a specific time frame on what remains to finish coursework.

The academic advisor reports that on occasion students have little idea about what they want to study in college and ask 'what should I do with my life?' In general when posed with these questions, the academic advisor refers the student to the on campus career and counseling center. The academic advisor is usually not a subject matter expert. To answer specific questions about the discipline, the academic advisor refers students to the department heads of various disciplines for example mechanical engineering, electrical engineering, civil engineering, etc. Often times, the academic advisor serves as a resource for literally pointing students in the right direction. She is asked on a daily basis for assistance in finding a particular room, building or professor's location (Williamson, 2013) (Williamson, 2013).

\subsection{What are the Common Complaints that Students Have}

Many students voice their disapproval regarding the time frame that transfer credits are processed. They often reach out to the academic advisor for assistance in expediting this process. These existing procedures tend to be very time consuming, but advisors should keep in mind that they are there to support the students and assist them with getting things accomplished.

Some students complain about having conflict with a certain professor. The advisor can begin with suggesting that they talk to the professor outside the classroom. Having a discussion can often resolve the conflict. In cases like these, the advisor tries to ask questions to gain the proper background and then offers suggestions on how to resolve these potential conflicts. One of the implied roles of an academic advisor is that of a student advocate. In some cases, the advisor can speak to the professor on behalf of the student. Students often seem to feel more comfortable talking to the advisor than the faculty member. This could be attributed to the warm, welcoming, passionate personality of the typical academic advisor. All of these are important qualities of an effective academic advisor. Taking time to listen to the students can help make them feel comfortable. Students may seek out the academic advisor more often than faculty members because they typically feel less threatened by them. They realize that their grade is not dependent on the impression they make on the academic advisor.

To balance out the workload of the academic advisor, each faculty member needs to realize the importance of proper advising and to help do their part to advise students in their areas of study. There is often insufficient advice from faculty or sometimes the advice is completely missing. Students sometimes complain faculty members need to be trained on proper advising procedures and their importance. Also, some students criticize faculty advisors who are not easily accessible. Some faculty advisors continue to refer students to the academic advisor rather than take the time to address the student's concerns. With the academic advisors having limited available due to the high demand from students, the School of Engineering needs more advisors (Williamson, 2013) (Williamson, 2013).

\subsection{What are some of the Things that Students Take for Granted}

Typically, students come in thinking that the advisor is always available. Because of the heavy work load, a single academic advisor is not as effective if bogged down with students not taking the time to book appointments. The office hours are posted and students are requested to make appointments; however, students keep coming in without the appointments and sometimes end up waiting for long times just to find out that another student, who made an appointment, will be served next. Recently, the advisor posted a sign indicating that appointments were necessary to see her. Despite that, it is observed that students call, email or simply walk in during the hours when the advisor is not available or is busy with other job duties. Some students have quick questions while others require long discussions. So a balance needs to be struck, which is a challenge in itself. Some students need to lay out the two or four year study 
plans. The plan can end up changing for various reasons including changes to the curriculum, the student changing to another engineering major or the schedule of the student changing due to work or other personal reasons. Students often come back several times for revisions to their plans. The academic advisor points out that having more knowledge is better than little knowledge so that if a question rises outside of her area of expertise she is aware of who the student should contact to get the correct answer. A warm welcoming attitude helps with the advising process. There are a few frequent visitors that come and just want to talk to their academic advisor about their activities outside of school or to share good news.

On the other hand, some only come when they are ready to fall off the cliff. Probation students need to be recognized so that they are helped before it becomes too late and they end up suspended from school. New students often have misconceptions that college will be just an extension of high school. These students tend not to have well established study habits often resulting in poor grades. Sometimes reaching out is hard during the registration time because of the demanding work load. Often, new students never respond despite being contacted and often those are the students who need the most guidance. In those situations, getting the faculty involved and having them reach out to the students would help tremendously.

Some students enter the university with the intent to transfer to another school. Ideally advisors want students to stay; however, if a program does not exist at the home institution, advisors need to show them the available options so that they can make an informed decision. Incoming transfer students often assume that their credits will be applied automatically. They are not aware that they should ask questions and double check for accuracy, making sure credits have been updated correctly. It is important that advisors take the necessary time to review transfer credits and assist these students in getting their credits properly applied (Williamson, 2013) (Williamson, 2013).

\subsection{What are Some of the Things Students Learn Rather Quickly}

If the advisor is welcoming and approachable, students learn quickly that she is helpful and end up coming back. It is important to assist students in creating a plan and reminding them the importance of following it. Students are advised to periodically review their individual plan. Career paths should be well defined and courses should be taken accordingly. Students should not take random classes that do not help towards their degrees. When students are guided rather than told what to do, they tend to experience a sense of capability (Williamson, 2013) (Williamson, 2013).

\subsection{What are Some Effective Advising Attitudes and Practices}

The following are some of the examples of the best practices for the academic advisors compiled from Missouri Western State University advising site (University, 2013) Develop positive relationships with students; Remain approachable and available to students; Maintain communication with students; Create a safe and relaxing environment; Provide accurate resources; Assist with empowering students to be self-reliant; Help students develop problem-solving skills; and Maintain professionalism.

Sometimes students feel like they are being ignored if no one responds to their questions. One student told the advisor that he was transferred five times on the phone before he received the answer to his question. A scenario like this could upset the students, discourage them and worse, turn them away from college. In another scenario, the advisor tried to answer a question related to a program of study outside the School of Engineering because their advisor was not available. However, the advisor is always quick to give the student the contact information of his/her primary advisor so that the student knows who to contact for future assistance. Academic advisors and faculty advisors alike should take the responsibility to welcome students and try to address their needs. Students are the customers of higher education. This is how it works in business world. A satisfied customer is likely to return and refer others (University, 2013) (University, 2013).

\subsection{How Do You Decide What Career is Best for an Undecided Student}

Both an academic advisor and faculty advisor should act as sources of knowledge, but should never make a decision for the students. There are several types of advice that can be given to students to help them choose a major. If a student is undecided, they are advised to take courses that would apply to all majors and then decide what path they want to pursue. The advisor does not and should not make decisions or career choices for the students. They are encouraged to explore various options and try to develop their area of interest. Below is a list of suggestions for undecided students.

- Refer students to the college bulletin

- Suggest that they talk to the department chairs

- Suggest that they talk to the course instructors

- Suggest that they talk to other students in a discipline

- Describe the course and program content to them directly

Just as choosing a major ultimately rests on the student, so does selecting a profession. It is observed that sometimes students want the advisor to tell them what to do as some students do not like making decisions or have not had the experience behind them to feel comfortable being in charge of their futures. It is imperative that advisors help guide the students to a resolution as best they can. Most importantly is helping the students feel empowered by realizing the 
potential they have. Sometimes an undecided student may display frustration at the lack of direct advice or if they do not have a decision made for them. The best practice is to help them recognize their interests by asking probing questions. If students are having a really tough time deciding between two different majors, they may consider taking a few courses in those disciplines of interest. Gaining background about the student may also help as well as emphasizing the importance of really enjoying what one does. Sometimes the ability to relay personal stories helps students discover connections. Also, any reference to culture, history etc. may help spur them on to come to their own conclusions (Williamson, 2013) (Williamson, 2013).

\section{Student Perspective}

To get student perspectives, a survey was developed and launched for students in the School of Engineering. The school has over 1,200 engineering students enrolled. In this survey, the students who did not declare some kind of engineering as their choice of study were not included. The response rate was approximately $30 \%$. As depicted in Figure 1 , more responses were received from senior students than those of other class standings. Given that more than $60 \%$ of the engineering students are freshmen and sophomore, this trend is counter intuitive. One would expect the freshmen and sophomore students seeking advice more than the senior students. This may be an indication of the fact that seniors are familiar with the advisor and therefore tend to seek help more often.

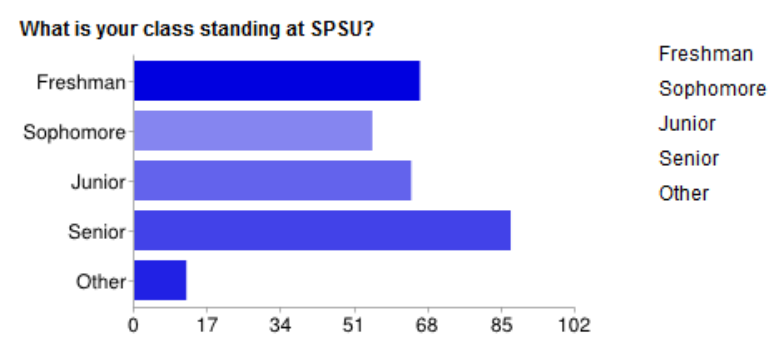

Figure 1. Class standing of participating students

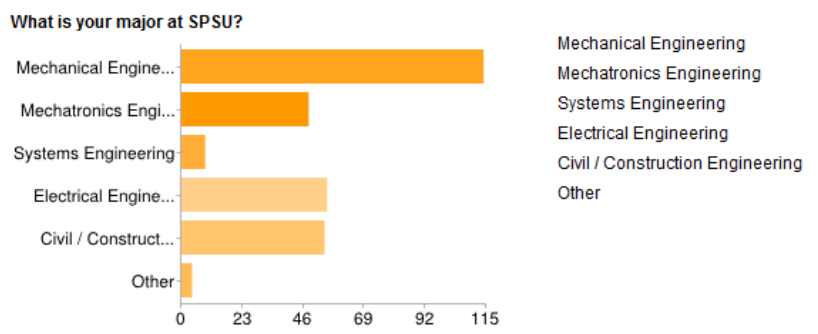

Figure 2. Majors of disciplines of participating students

The distribution of major or discipline of study of participating students is a fair representation of the distribution of students enrolled at SPSU. Distribution of students who participated in the anonymous study is shown in Figure 2. The most popular major is mechanical engineering. Systems engineering was recently introduced and therefore has limited enrollment. Mechatronics, electrical, and civil engineering have approximately the same number of students.

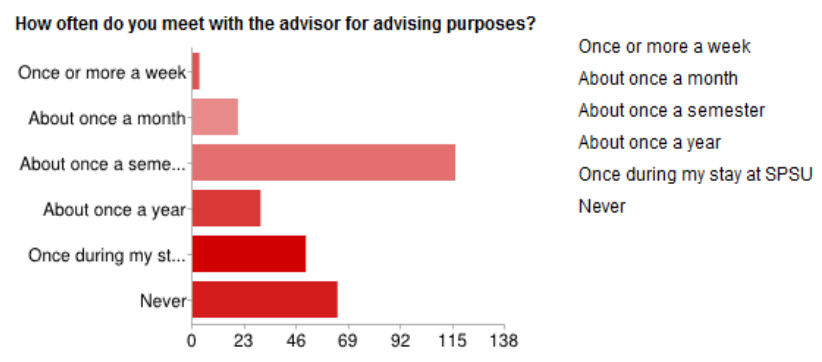

Figure 3. Histogram of the Frequency with which Students meet with the Academic Advisor

Figure 3 shows the distribution of how frequently the students meet with the academic advisor for advising purposes. It can be seen that approximately $50 \%$ of the students meet with the advisor once or more in a semester. That averages to 7 students per day for every working day of the semester. Given that it takes approximately one hour to meet with one student, for a single academic advisor, this is a heavy work load. This leaves her with very little time to respond to the emails and phone calls, read articles and other published materials to stay current in the field, participate in professional development or engage in other related activities. This heavy work load can result in a number of willing students not being able to schedule a meeting with the advisor. This lack of availability can result in student dissatisfaction which can lead to attrition. There is a clear need for more advisors and sharing of the current advisor load. As shown in Figure 3, a number of students come back to meet with the advisor multiple times in a semester. Some of these students can be asked to meet with the faculty advisors first to help answer their questions. On the other side of the spectrum, there are approximately $50 \%$ of the students who meet with the advisor once a year or less. Approximately $20 \%$ of the students never meet with the advisor. These are probably the students who either need no help because they have figured out exactly what they want to do or more likely, students who do not know what they want to study and do not know where to go to seek help. These are the students who need to be targeted to make sure their needs are being served properly.

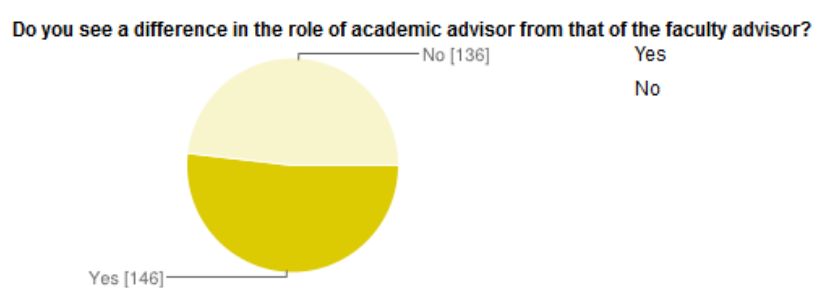

Figure 4. Difference in Role of the Academic versus Faculty Advisor 


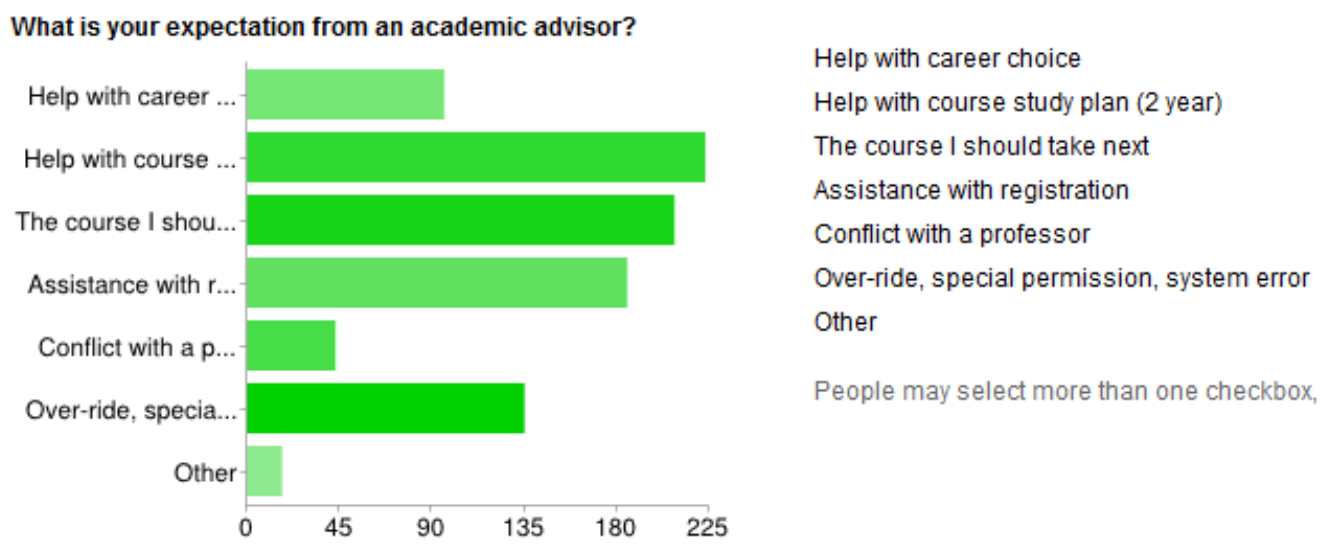

Figure 5. Expectations from an Academic Advisor

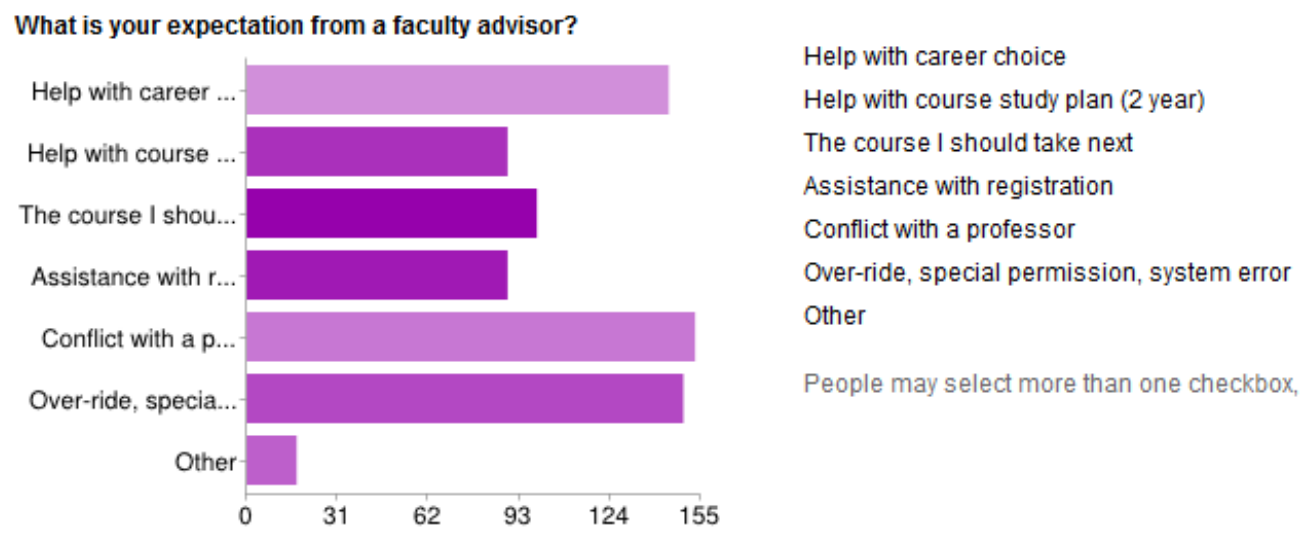

Figure 6. Expectations from a Faculty Advisor

Figure 4 indicates that students do not see a difference in the role of an academic advisor when compared to that of a faculty advisor. But when students are asked to list the various roles, it can be seen in Figure 5 that academic advisor is expected to help students with the course study plan as well as assisting with which courses should be taken when. The academic advisor is also expected to help with the registration. On the other hand, as shown in Figure 6, faculty advisors primary role according to students is to assist them with advisement about career choices. Students also tend to approach their faculty advisors if they have a conflict with their course instructor or professor. Other requests for faculty advisors include getting over-rides into certain courses that may be closed or unavailable to students do to pre-requisite errors for example.

In summing up the results, the survey reveals that only about half of the students surveyed see an academic advisor on regular basis. It also reveals that surprisingly, around $20 \%$ of the students never seek help from the advisor. This could be attributed to the limited availability of the advisor, which further emphasizes the need of having multiple academic advisors in an engineering school. The author's opinion is that the ideal ratio of academic advisor to student ratio is 1-100. For a small engineering school like SPSU, with a new engineering program, it is imperative that attention is given to this serious matter. The University System of Georgia (USG) is placing increased emphasis on institutions improving Retention, Progression and Graduation (RPG) rate. The key to improve the RPG rate is to have timely, effective, efficient, and accurate advising available to students.

\section{Conclusions}

Well advised students are likely to continue enrolling in classes, staying on track by following their plan of study, and progressing towards graduation all while enjoying their time as a college student because they are well informed and aware of what it will take to be successful. Advising is labor intensive and it is important that advisors seek to have a balance in their jobs so as not to create burn-out. The role of the advisor is crucial for all students. Computer assisted advisement programs exist that can help alleviate the workload of an academic advisor. The academic advisor indicates that students are often shy about sharing their concerns with the faculty members because they may feel intimidated or are concerned that their grade may be affected if they express themselves openly. Students feel comfortable with sharing their needs with a welcoming academic advisor. 
Some characteristics of a good academic advisor are highlighted throughout this paper. A good advisor should listen to the student and give them all the available options. Students will appreciate the value of useful advice and are therefore likely to return for more advice, which in turn will help increase student enrollment, engagement and graduation rates. To successfully serve all the students, the number of academic advisors must be increased. At the same time, some of the workload of the academic advisors can and should be shared by the faculty advisors.

\section{REFERENCES}

[1] CourseShark. (2013, October 15). CourseShark. Retrieved from CourseShark: www.CourseShark.com

[2] E., D., \& Miller, W. B. (1979). Group Interaction as a Vehicle to Facilitate Faculty-Student Advisement. Journal of College Student Personnel, v20 n3 p253-57.

[3] Frost, S. H. (1993). Developmental advising: Practices and attitudes of faculty advisors. NACADA Journal, Volume $13(2), 15-21$.

[4] Grupe, F. H. (2002, Dec). Student Advisement: Applying a Web-Based Expert System to the Selection of an Academic
Major. College Student Journal, Vol. 36, No. 4.

[5] Habley, W. R. (2009). Academic Advisement: The Critical Link in Student Retention. An International Conference on Student Success (pp. 1-62). Chicago, IL: The Education Policy Institute.

[6] Jenkins, J. M. (1992). Advisement Programs: A New Look at an Old Practice. Washington D.C. : National Association of Secondary School Principals.

[7] Lowe, A. \&. (2002). Academic Advising: Views of the Givers and the Takers. Journal of College Student Retention, 2 (12), 93-108.

[8] Selke, M. J., \& Wong, T. D. (1993). The Mentoring-Empowered Model: Facilitating Communication in Graduate Advisement. ERIC Clearinghouse, ED358089.

[9] T. M. Rao, S. C. (1987). Advisor - an expert system for student advisement. CSC ' 87 Proceedings of the 15th annual conference on Computer Science (pp. 32-35). New York, NY: ACM.

[10] University, M. W. (2013, October 15). Best Practices for Academic Advisors. Retrieved from Missouri Western State University:

http://www.missouriwestern.edu/advising/best-practices.asp

[11] William L. Heward, T. E. (1990). The Master's Thesis in Applied behavior analysis: Rationale, Characteristics, and Student Advisement Strategies. Columbus, OH: Ohio State University. 